\title{
ENTRE A MEMÓRIA E O DESEJO DAS CIDADES INVISÍVEIS: A CENOGRAFIA DO DISCURSO LITERÁRIO
}

\section{BETWEEN MEMORY AND DESIRE OF INVISIBLE CITIES: A LITERARY SCENOGRAPHY SPEECH}

\author{
Ernani Cesar de Freitas* \\ Fabiane Verardi Burlamaque \\ Débora Facin ${ }^{* * *}$
}

RESUMO: A temática deste artigo propõe o pensar e o produzir inovação na área dos estudos literários. O objetivo foi analisar a(s) cenografia(s) da obra As cidades invisíveis, de Calvino, a(s) qual(is) se constroem de forma não linear, mediante o reconhecimento que o hipertexto se faz presente em um escrito impresso, utilizando conceitos sobre cenografia (MAINGUENEAU, 2006) e hipertexto (LÉVY, 2009; LÉVY, 2010). O estudo mostra que é preciso repensar o convencionalismo utópico de que o texto literário se sustenta na linearidade.

PALAVRAS-CHAVE: Cidades invisíveis. Cenografia. Hipertexto. Inovação. Literatura.

ABSTRACT: The theme of this article proposes producing thinking and innovation in the field of literary studies. The objective was to review (s) set design (s) of the work Invisible Cities, Calvino, a

* Doutor em Letras (PUCRS), com pós-doutorado em Linguística Aplicada e Estudos da Linguagem (PUC-SP/LAEL); professor do Programa de Pós-graduação em Letras da Universidade de Passo Fundo. E-mail: ecesar@ upf.br

** Doutora em Letras (Teoria Literária) pela Pontifícia Universidade Católica do Rio Grande do Sul; professora do Programa de Pós-graduação em Letras da Universidade de Passo Fundo. E-mail: fabianevb@uol.com.br

${ }^{* * * *}$ Mestre em Letras pela Universidade de Passo Fundo. E-mail: deborafacin@upf.br 
(s) which one (s) are constructed in a nonlinear manner, through the recognition that hypertext is present in a written form, using concepts of scenography (MAINGUENEAU, 2006) and hypertext (LÉVY, 2009; LÉVY, 2010). The study shows that we need to rethink the conventionality of the utopian literary text is based on linearity. KEYWORDS: Invisible Cities. Scenography. Hypertext. Innovation. Literature. 


\section{ENTRE A MEMÓRIA E O DESEJO DAS CIDADES INVISÍVEIS: A CENOGRAFIA DO DISCURSO LITERÁRIO}

\section{INTRODUÇÃO}

A iniciativa em produzir este artigo tem um motivo: exercitar o pensar e o produzir inovação na literatura, nos estudos literários. Sem nenhuma pretensão de estabelecer uma reflexão hermética acerca do que vem a ser inovação, este ensaio visa a propor um estudo do texto literário por uma interface entre a [nossa] leitura - a hipertextual - com as teorias discursivas - a cenografia pensada por Dominique Maingueneau (2006). É sob este enfoque que o sentido de inovar se consolida: nossa filiação às contribuições do teórico francês para desvendar o mistério das cidades em Ítalo Calvino. Acreditamos que o diálogo entre discurso e literatura não é só produtivo, como também inovador. E, uma vez que o texto literário só é assim considerado por apresentar "marcas" de pertencimento à literatura (MAINGUENEAU, 2006), por que não inovar no sentido de aproximá-la ao campo discursivo?

A nossa concepção de literatura como discurso requer uma leitura particular da obra de Calvino: a quebra da linearidade. Isso porque não acreditamos que a leitura de um texto literário se reduza a uma ordem sequencial. Acrescente-se a esse estrato o viés teórico por nós adotado: o da enunciação. O leitor, ao visitar cada cidade da obra de Calvino, é convidado a ressignifi- 
car o sentido figurativizado em uma arquitetura geométrica, mas que tende a tematizar, em cada espaço, o embaraço que caracteriza a existência humana.

Em princípio, pode parecer estranha a iniciativa de relacionar a ideia de hipertexto a um discurso literário em meio impresso; não obstante, ressaltamos que essa ciência não é contemporânea, tampouco se limita apenas a textos disponíveis em meio eletrônico. Esse novo estrato de leitura advém de linguagens que não mais constituem estruturas justapostas e engessadas em sua composição, mas sim um novo conceito do que vem a ser linearidade. É por esse motivo que nos atrevemos em afirmar que é pela linguagem que o hipertexto se consolida.

Com base nisso, estabelecemos a questão norteadora deste estudo, qual seja: como proceder a uma análise da obra As cidades invisíveis, de Ítalo Calvino (1990) mediante as categorias de cenografia e hipertexto para buscarmos o(s) sentido(s) ante a multiplicidade de significações que perpassam o enigmático símbolo das cidades? Tal questionamento implicou a delimitação de um roteiro metodológico detalhado que contempla desde a escolha das categorias teóricas até a opção de leitura entre as várias que podem ser realizadas do texto de Calvino.

Esta pesquisa caracteriza-se como descritiva e bibliográfica com análise qualitativa. A fundamentação teórica concentra-se em Maingueneau (2006), sobre a cenografia, e em Lévy $(2009,2010)$, a respeito do hipertexto. Com a finalidade de atendermos à questão norteadora e ao objetivo de pesquisa, organizamos este texto da seguinte maneira: em primeira instância, buscamos situar a literatura no campo enunciativo-discursivo. Na sequência, dedicamos um espaço ao hipertexto com o propósito de elucidarmos que tal definição não está necessariamente ligada apenas a discursos em rede, mas sim a enunciados, ao próprio discurso. Após o espaço teórico, os procedimentos metodológicos esclarecem os dispositivos utilizados para fins de análise, bem como o itinerário de leitura que nos pareceu mais convidativo para um estudo dessa natureza. Por fim, a análise do corpus e as considerações, que revelam algumas conclusões e possibilidades de estudos decorrentes de obras literárias investigadas sob o prisma discursivo. 


\section{A LITERATURA COMO DISCURSO: UMA POSTURA INOVADORA}

É tão somente a linguagem que distancia o texto literário dos demais gêneros não literários. Barthes (2004), em O rumor da língua, faz uma distinção entre a linguagem literária e a científica. Esta, segundo o autor, caracteriza-se como instrumento e tem a finalidade de tornar lúcidas as operações advindas do âmbito científico; é mediante a linguagem que os indivíduos manifestam suas observações, experimentações e resultados. É tão somente a forma verbal que possibilita a divulgação dos conteúdos elaborados na ciência. Já a linguagem literária, ao contrário da primeira, não pode ser concebida como instrumento; “a linguagem é o ser da literatura, seu próprio mundo: toda a literatura está contida no ato de escrever, e não mais no de 'pensar', de 'pintar', de 'contar', de 'sentir' [...] a literatura se vê hoje sozinha a carregar a responsabilidade inteira da linguagem [...]” (BARTHES, 2004: 5).

Nesse particular, a literatura só ganha corpo pela linguagem, esta não preexiste àquela; é na e pela linguagem que a cultura do mundo se consolida literariamente. A tradução da cultura mediante o texto literário faz com que percebamos a obra sob a perspectiva da comunicação. Maingueneau (2006: 36) é pontual ao mencionar que a obra literária não se constitui como um universo fechado, ou seja, "é a multiplicidade de quadros cognitivos e práticas que lhe conferem sentido". Maingueneau (2006) revela que o discurso literário é, por excelência, a manifestação dialógica de linguagem. "[...] o discurso não se encerra na interioridade de uma intenção, sendo em vez disso força de consolidação, vetor de um posicionamento, construção progressiva, através do intertexto, de certa identidade enunciativa e de um movimento de legitimação do espaço de sua enunciação" (MAINGUENEAU, 2006: 43).

Essa tese permite atentar para comportamentos imaturos que tendem a separar os estudos linguísticos dos literários em razão do equívoco que permeia as duas vertentes: de um lado, a linguística consagrada em estudar textos caracterizados como não literários; por outro, a literatura com a função de explorar corpus de ordem estética. Essa postura "consagrada" é inconcebível a partir do momento em que a literatura constitui, de fato, um discurso e é no discurso que a escrita literária se consagra literatura. 
Uma vez o texto literário concebido pelo prisma da enunciação, o que há não é mais a divisão na qual o texto consiste em um plano e o contexto é outra propriedade, distante da obra; na verdade, o conteúdo da obra é demarcado pelas condições de enunciação, ou melhor,

[...] as obras falam de fato do mundo, mas sua enunciação é parte integrante do mundo que se julga que elas representem. Não há, de um lado, um universo de coisas e atividades mudas e, do outro, representações literárias dele apartadas que sejam uma imagem sua. Também a literatura constitui uma atividade; ela não apenas mantém um discurso sobre o mundo, como produz sua própria presença nesse mundo.

(MAINGUENEAU, 2006: 44)

A obra literária, mediante a representação de mundo no texto, denuncia as condições de sua enunciação. Isso implica a configuração da cena da enunciação, a qual não se reduz nem ao texto, nem ao exterior; é pela cena que o discurso é validado e, com ele, a representação cultural exterior.

Todo discurso implica uma situação de enunciação, e com a obra literária não é diferente. No universo literário, Maingueneau (2006: 250), quando se refere à situação de enunciação, faz este questionamento: "qual é a situação de enunciação de uma obra? Seria possível responder que são as circunstâncias de sua produção, sua situação de comunicação: ela foi escrita durante certo(s) período(s), em certo(s) lugar(es), por certo(s) indivíduo(s)". Não obstante tal inquietação, essas respostas são insuficientes ao caracterizar uma obra como dispositivo de comunicação. Se falarmos em data ou lugar empiricamente, por exemplo, a divagação em termos de recepção do discurso literário continua.

Ao conceber a obra literária sob a situação de comunicação, consideramo-la exteriormente e, a partir da situação de enunciação, a obra passa a ser observada em seu interior, mediante o processo linguístico que a constitui. Desse modo, adotamos pressupostos teóricos da cena de enunciação, isto é, um texto configura-se por meio de "rastro de um discurso em que a fala é 
encenada" (MAINGUENEAU, 2006: 250). No momento em que percebemos o texto literário como uma cena enunciativa, distanciamo-nos de análises circunstancias de contemplar ou o sistema linguístico isolado ou o contexto de uma obra como se esta suportasse duas concepções justapostas. Falar em um discurso encenado significa que "a enunciação, em seu desenvolvimento, esforça-se para justificar seu próprio dispositivo de fala. Tem-se, portanto, um processo em espiral: na sua emergência, a fala implica uma certa cena de enunciação, que, de fato, se valida progressivamente por meio da própria enunciação" (CHARAUDEAU; MAINGUENEAU, 2008: 96).

A cena de enunciação compreende três cenas, quais sejam: a englobante, a genérica e a cenografia. "Juntas, elas compõem um 'quadro' dinâmico que torna possível a enunciação de um determinado discurso" (FREITAS, 2010: 179). A cena englobante refere-se ao tipo de discurso, o qual pode ser político, religioso, administrativo, etc. $\mathrm{O}$ discurso literário sempre está vinculado a uma cena englobante; todavia, a noção de cena englobante apenas não é suficiente para caracterizar a obra literária. Na verdade, todo enunciado literário é manifestado por um gênero; pode-se então falar de cena genérica (MAINGUENEAU, 2006). A cenografia é construída pelo próprio texto e não diz respeito a um espaço físico, como se o enunciador pertencesse a um ambiente "emoldurado", mas sim a um espaço que é validado por meio da própria enunciação. A cenografia implica um processo de enlaçamento paradoxal entre as cenas, ou seja, a fala supõe uma situação de enunciação que é validada à medida que a própria enunciação se consolida (MAINGUENEAU, 2006).

A noção de cenografia comporta a ideia teatral associada à grafia; ambas as dimensões compõem um processo pelo qual garante a legitimidade da obra. Por exemplo, o romantismo não se consolida tão somente pelo conteúdo que apresenta nas obras, mas sim pela forma que se manifesta; é como se fosse um tratado de enlaçamento, "dando a ver ao leitor um mundo cujo caráter convoca a própria cenografia que o propõe e nenhuma outra: através daquilo que diz, o mundo que ela representa, a obra tem de justificar tacitamente essa cenografia que ela mesmo impõe desde o início" (MAINGUENEAU, 2006: 253). A literatura, assim, associa o seu dizer às condições de legitimação de seu dizer. 
A cenografia, também, dispõe de algumas propriedades. Maingueneau (2006), no âmbito da literatura, especifica as cenas mostradas e as validadas. Quanto à cena mostrada, o autor ilustra por meio da fábula: esse gênero não diz que o conteúdo é um apelo a referências de mundo; é tão somente as marcas textuais que "mostram" essa finalidade. Sobre as cenas validadas, as obras podem basear sua cenografia em outros gêneros já validados, como é o caso do discurso do político, da fala da empregada. Não obstante tais delimitações acerca da cena mostrada e da cena validada, "não é preciso que a situação de enunciação mostrada pela obra esteja em perfeita consonância com as cenas validadas que ela reivindica em seu texto, nem que estas últimas formem um conjunto homogêneo" (MAINGUENEAU, 2006: 257). A cenografia da obra, em sua totalidade, consiste no diálogo entre os elementos; o que é mostrado, na verdade, só toma corpo mediante a própria enunciação.

Portanto, falar em cenografia no universo literário é articular a obra de modo autônomo às suas condições de produção; a literatura constrói sua identidade e representação de mundo em seu discurso que lhe é próprio. É ilusório pensarmos que a obra tem a mera função de transmissão de conteúdos. Mais do que uma metodologia, analisar a obra literária mediante a cenografia é reconhecer o conteúdo de um texto literário o qual só tem validade pelo próprio texto, ou seja, a cenografia "de onde vem a fala é precisamente a cenografia necessária para enunciar como convém” (MAINGUENEAU, 2006: 253); tanto é que a cenografia não se reduz a um procedimento, uma vez que ela também está associada à configuração histórica. Voltando ao exemplo do romantismo, não é o conteúdo mundano que o constitui romantismo, mas sim as marcas que o denunciam e que o validam dessa maneira.

A linha teórica adotada por Maingueneau (2006), especialmente quanto à cenografia, é inovadora, conforme nosso entendimento, tanto ao analista de discurso - porque este não se restringe nem ao plano linguístico (estrutural), nem às interpretações românticas do texto - quanto à possibilidade de se fazer interfaces com outras áreas do saber. A cenografia não se limita a investigar textos considerados não literários, isso porque o teórico francês entende a literatura como discurso. A perspectiva linguístico-discursiva volta-se, portanto, para o que se permite falar em determinado discurso, 
consoante o posicionamento que o constitui. É a cenografia que se esforça, à medida que avança discursivamente, para validar o seu dizer.

No caso da obra de Calvino, As cidades invisíveis, é possível relacionar a cena literária com [nosso] modo de ler a obra: hipertextual. É por meio da deslinearização, da ambiguidade, da inquietação das personagens, das paisagens múltiplas reveladas em cada cidade e que não se fecham em si que nos viabiliza construir cenografias variadas [no e pelo discurso] a partir de um olhar hipertextual. São as marcas hipertextuais que fazem das cidades invisíveis múltiplas cenografias.

\section{NOVA ESTAÇÃO, NOVA TRIBO: AS CIDADES E A METÁFORA DO HIPERTEXTO}

Um texto já é sempre um hipertexto

(PIERRE LÉVY, 2010)

"Quando conhecer todos os emblemas - perguntou Marco -, conseguirei possuir o meu império, finalmente? E o veneziano: - Não creio: nesse dia, Vossa Alteza será um emblema entre os emblemas" (CALVINO, 1990: 26). É com essa passagem, a qual finaliza o primeiro capítulo da obra As cidades invisíveis, de Calvino (1990), que principiamos este espaço teórico. Quando, em sua inquietude, Marco espera de fato conquistar o seu império, é como se o espaço conhecido ganhasse novas definições, novos sentidos. Assim como as cidades invisíveis se recriam quando do contato com outra geografia, a palavra constitui-se por outras para que haja sentido. São as marcas de que o hipertexto se constrói enunciativa e discursivamente.

A ideia de importarmos a proposta da metáfora do hipertexto, de Lévy (2010), para analisarmos um corpus em meio impresso, justifica-se pela insatisfação com a hierarquia e com a ruptura de estruturação textual. A leitura hipertextual requer uma postura que não mais se limita ao trajeto linear, à disposição clássica declarada por Aristóteles na qual a obra se organizava por início, meio e fim. "O jogo da comunicação consiste em, através de mensa- 
gens, precisar, ajustar, transformar o contexto compartilhado pelos parceiros" (LÉVY, 2010: 22). Nesse particular, este trabalho dedica-se a conceber o hipertexto a partir das redes de significação encontradas no discurso - As cidades invisíveis -, ou seja, mediante as marcas linguísticas que orientam para a multiplicidade de representações, e não o suporte tecnológico em si. Embora a concepção do hipertexto ganhe corpo com a disseminação das tecnologias da informação, a interação não se consolida apenas por intermédio de máquinas, mas sim na construção do próprio texto.

A metáfora do hipertexto dá conta da estrutura indefinidamente recursiva do sentido, pois já que ele conecta palavras e frases cujos significados remetem-se uns aos outros, dialogam e ecoam mutuamente para além da linearidade do discurso [...] O vocábulo "texto", etimologicamente, contém a antiga técnica feminina de tecer. E talvez o fato deste tricô de verbos e nomes, através do qual tentamos reter o sentido, ser designado por um termo quase têxtil não seja uma coincidência (LÉVY, 2010: 73).

Lévy (2010) dedica-se à noção do hipertexto no meio digital e menciona seis características que o consolidam: princípio de metamorfose, princípio de heterogeneidade, princípio de multiplicidade e de encaixe das escalas, princípio de exterioridade, princípio de topologia, princípio de mobilidade dos centros.

Em atenção às considerações advindas de Lévy $(2009,2010)$ acerca da hipertextualidade, selecionamos estas categorias que configuram o hipertexto e que fazem parte da análise da obra As cidades invisíveis: a composição em rede e entre nós (LÉVY, 2010); as possibilidades de interação - essa propriedade é elementar, pois serve como norte às escolhas de leitura no corpus deste artigo; a reversibilidade.

Quando da concepção do texto como uma rede, o conceito de linearidade cede espaço ao de multiplicidade; isso é possível mediante a renegociação entre os textos e o processo de conexão. No caso da obra literária, em es- 
pecial As cidades invisíveis, não podemos proceder a uma leitura canônica, na esperança de definirmos o início, meio e fim. A grandeza da arquitetura dessa obra está nos efeitos de sentido decorrentes das peculiaridades de cada cidade, ou de cada leitura - seja da passagem de uma cidade a outra, seja pelo diálogo entre os personagens Marco Polo e Kublai Khan, seja pela temática.

Ao retomarmos a teoria dialógica da linguagem e associarmos algumas características do hipertexto como metodologia para a leitura do corpus deste trabalho, assinalamos o afastamento do monologismo na comunicação, ou da centralização enunciativa; evidencia-se, portanto, "o hipertexto como a reserva ecológica, o sistema sempre móvel das relações de sentido” (LÉVY, 2010: 73). Embora a leitura hipertextual seja caracterizada por significações múltiplas, é importante ressaltar que as distintas possibilidades não implicam a concessão de quaisquer atribuições ao texto. É o que aponta Chartier (1991): os leitores, por sua vez, "manejam objetos cujas organizações comandam sua leitura, sua apreensão e compreensão partindo do texto lido [...] é preciso considerar que as formar produzem sentido". Tais organizações fazem parte do hipertexto e consistem na propriedade de reversibilidade, o que significa que os sentidos de uma obra resultam das combinações feitas tanto em nível paradigmático quanto em nível sintagmático. Eis um princípio que possibilita analisar uma obra de diversas maneiras. É o que bem observa Barthes (2004: 64) em atenção à obra literária: "um texto é feito de escrituras múltiplas, oriundas de várias culturas e que entram umas com as outras em diálogo, em paródia, em contestação, mas há um lugar onde essa multiplicidade se reúne, e esse lugar não é o autor [...] é o leitor". É o leitor quem virtualiza ${ }^{2}$ o texto, quem escolhe a forma de leitura, seja por meio de sua orientação no meio impresso, seja pela seleção de links os quais o conduzirão a outros textos.

Marcuschi (2006) concebe esse processo de deslinearização como um preceito-base para a construção do sentido. Linguisticamente, o autor afirma que a linearidade existe na estrutura da palavra, quando da disposição das letras, ou na construção da frase, quando da obediência às normas sintáticas; no entanto, em termos de texto, essa hierarquia se desfaz, uma vez que um enunciado pode ser lido de maneiras variadas.

É sob essa constatação que o hipertexto, como forma de escrita e leitura, está longe de se abreviar tão somente ao suporte - computador. Uma obra 
literária, por exemplo, pode ser disponibilizada em meio eletrônico, mas não necessariamente apresentar em sua composição as propriedades do hipertexto. Ao contrário, outra obra literária pode ser divulgada em meio impresso e, ao mesmo tempo, provocar uma leitura incômoda, daquelas em que o leitor precisa "levantar a cabeça", como diria Barthes (2004: 26), construída textualmente como se fosse uma rede, que exige interação do leitor e que não esteja aprisionada pela própria palavra. As cidades invisíveis é um exemplo de leitura hipertextual e perturbadora.

\section{PROCEDIMENTOS METODOLÓGICOS E ANÁLISE}

O corpus de pesquisa compreende a obra intitulada As cidades invisíveis, de Ítalo Calvino, publicada em 1990. Trata-se de um estudo de caráter descritivo e abordagem qualitativa. Instiga-nos a desenvolver um estudo dessa natureza, pois, a partir da definição do quadro teórico e posterior seleção do corpus, podemos descrever e analisar como se constrói a(s) cena(s) das "cidades" na literatura de Calvino. A escolha do corpus justifica-se, além do gosto pessoal, a importância de contemplar uma literatura que possa ilustrar as possibilidades e inquietudes do universo fictício, sobremaneira romper com pressupostos tradicionalistas de recepção do texto literário, ou seja, de que toda obra demarca pontualmente o início, meio e fim. Acrescente-se a isso nossa busca de pensar e produzir inovação, nos estudos literários, ao propor um diálogo entre uma teoria provinda dos estudos discursivos com a literatura. Mediante as características do hipertexto, o leitor pode escolher o caminho a seguir em busca do enigma de cada lugar a descobrir, de cada peculiaridade que singulariza cada cidade.

Cenografia e hipertexto são termos-chave à nossa análise; isso porque o exame do corpus depreende-se de uma leitura que é hipertextual, ou seja, caracteriza-se como uma trama, é interativa e a própria estrutura do livro permite a recepção do leitor em caráter múltiplo. Para melhor organização da análise, consideramos os seguintes procedimentos metodológicos:

a. primeiramente, procedemos a uma leitura geral consoante a escolha definida - recorte temático memória e desejo e os diálogos entre Marco Polo 
e Kublai Khan que iniciam e finalizam cada capítulo - para posterior análise da obra de Calvino (1990), As cidades invisíveis, à luz da cena enunciativa (MAINGUENEAU, 2006) e do hipertexto Lévy (2009, 2010);

b. em segundo momento, identificamos as evidências linguísticas caracterizadas pelas marcas linguísticas as quais possibilitam a construção $\mathrm{da}(\mathrm{s})$ cena(s) enunciativa(s);

c. por fim, inscrevemos a obra de Calvino (1990) em um quadro de orientação hipertextual, identificando como o texto se orienta sob essa configuração. Nesse momento, os conceitos de Lévy $(2009,2010)$ e Marcuschi (2006) são bem-vindos, uma vez que o desenvolvimento deste artigo partiu da leitura hipertextual em meio impresso.

As cidades invisíveis, de Îtalo Calvino (1990), está assim estruturada: são nove capítulos; destes, o primeiro e o nono dispõem de dez cidades e os demais, cinco. Cada capítulo é iniciado e finalizado com diálogos entre o viajante veneziano Marco Polo e Kublai Khan. Além disso, a obra apresenta onze temáticas relacionadas às cidades: memória, desejo, símbolos, delgadas, trocas, olhos, nome, mortos, céu, contínuas, ocultas. Tal estruturação foge a organizações de textos clássicos, uma vez que as possibilidades de leitura são múltiplas e a participação do leitor é bem-vinda nas lacunas deixadas no texto acerca dos enigmas que constituem cada cidade. As cidades invisíveis não corresponde a uma literatura abreviada em um só significado. Temos um significante - cidades - e para ele uma série de conceitos. Obviamente que, quando mencionamos a pluralidade de significados, não estamos induzindo a explorações folclóricas da obra nas quais qualquer interpretação seria válida. A complexidade que envolve o texto de Calvino se constrói no próprio texto e somente a partir deste é que podemos depreender a pluralidade de cenas enunciativas com base em uma leitura hipertextual.

A arquitetura de As cidades invisíveis é construída coletivamente em uma perspectiva de dependência, ligação essa que se configura não em um plano no qual a trama da obra careça da evolução da passagem de uma cidade a outra - até porque o leitor pode optar pelo roteiro que melhor lhe convier -, mas sim na subordinação que suscita mistério para a elaboração de cada mosaico que compreende as cidades. E, para isso, é necessário atentar a particularidades que se aquietam na memória e que se despertam no desejo. 
Para este artigo, definimos dois roteiros de leitura: o primeiro objetiva a relação entre a temática da memória e a do desejo; o segundo é dedicado aos diálogos entre Marco Polo e Kublai Khan. Poderíamos realizar, entre as várias, três trajetórias: pela linearidade e, dessa forma, explorando minuciosamente cada cidade; pela temática e a partir desta averiguar as associações dela decorrentes; pelos diálogos entre Marco Polo e Kublai Khan. Devido ao espaço e características do gênero artigo científico, aqui tratado, neste trabalho não é possível contemplar as várias possibilidades que a obra nos oferece em razão do espaço limitado em termos de extensão. Assim, o que nos pareceu mais convidativo foi o recorte temático e os diálogos que iniciam e finalizam cada capítulo.

No que se refere às cenas de enunciação, Maingueneau (2006) as classifica em três categorias: a cena englobante, a genérica e a cenografia. Nosso corpus de estudo assim se define: a cena englobante é o discurso literário e a genérica compreende o romance. No entanto, apenas essas duas cenas não são suficientes para especificar as atividades discursivas, isso porque o leitor pode se ver diante de variadas cenografias em uma mesma obra. A cenografia "que é tanto condição como produto da obra, que ao mesmo tempo está 'na obra' e a constitui, que são validadas os estatutos do enunciador e do co-enunciador, mas também o espaço (topografia) e o tempo (cronografia) a partir dos quais a enunciação se desenvolve." (MAINGUENEAU, 2006: 252, grifo do autor).

A obra de Calvino (1990) inicia-se com um texto narrado em terceira pessoa que retrata a dúvida se Kublai Khan acredita ou não nos relatos de Marco Polo acerca das cidades conhecidas por Marco Polo - todos os diálogos entre os dois são destacados em itálico. Ainda que As cidades invisíveis principie sob estado de incerteza por parte de Kublai Khan, essa imprecisão é contornada mediante o jogo figurativo: "Somente nos relatórios de Marco Polo, Kublai Khan conseguia discernir, através das muralhas e das torres destinadas a desmoronar, a filigrana de um desenho tão fino a ponto de evitar as mordidas dos cupins" (CALVINO, 1990: 10). É a partir desse plano figurativo que a primeira cidade pertencente à temática memória se apresenta de modo absolutamente feminino - todas as cidades comportam nomenclaturas femininas. O nome dela é Diomira, "cidade com sessenta 
cúpulas de prata, estátuas de bronze de todos os deuses, ruas lajeadas de estanho, um teatro de cristal, um galo de ouro que canta todas as manhãs no alto de uma torre. Todas essas belezas o viajante já conhece por tê-las visto em outras cidades" (CALVINO, 1990: 11).

Nesse fragmento do texto, percebemos o processo inicial de legitimação da obra. A cena de enunciação apresenta-se "no próprio movimento em que se desenrola." (MAINGUENEAU, 2006: 250). Isso significa que, ao mesmo tempo que o leitor é convidado a conhecer a cidade de Diomira, ele é reportado a outros lugares que também comportam as belezas de Diomira. Tem-se, nesse momento, uma cena enunciativa - narrada predominantemente no presente - que se constrói por marcas linguístico-discursivas exclusivas do hipertexto. Não basta, pois, fechar-se em Diomira. Isso porque a obra de Calvino se inicia no quadro figurativo da memória e é a partir desse projeto que as demais temáticas se ramificam. Segundo Maingueneau (2006: 253), "a obra se legitima criando um enlaçamento, dando a ver ao leitor um mundo cujo caráter convoca a própria cenografia que o propõe e nenhuma outra: através daquilo que diz, o mundo que ela representa, a obra tem de justificar tacitamente essa cenografia que ela mesmo impõe desde o início."

A potencialidade do conceito de cenografia advindo de Maingueneau (2006) para a leitura da obra de Calvino (ou qualquer outra obra literária) reside no fato de que texto e mundo não compreendem conceitos isolados. A enunciação de uma obra não se configura na exterioridade - marcas empíricas -, mas na discursividade, na cena que a origina e, ao mesmo tempo, valida seu dizer,

mas a peculiaridade desta é que quem chega numa noite de setembro, quando os dias se tornam mais curtos e as lâmpadas multicoloridas se acendem juntas nas portas das tabernas, e de um terraço ouve-se a voz de uma mulher que grita: uh!, é levado a invejar aqueles que imaginam ter vivido uma noite igual a esta e que na ocasião se sentiram felizes

(CALVINO, 1990: 11). 
As marcas textuais revelam-se nesse fragmento desta maneira: a figura do enunciador responde ativamente às belezas de Diomira a partir do momento em que ele insere diretamente o discurso de outrem, neste caso o grito da mulher - uh!. Isso implica que "a cenografia legitima um enunciado que, em troca, deve legitimá-la, estabelecer que essa cenografia de onde vem a fala é precisamente a cenografia necessária para legitimar o que convém.” (MAINGUENEAU, 2006: 253). Essa construção atribui um sentido ímpar ao enunciado, pois garante a particularidade da cidade Diomira, é o grito da mulher que provoca a originalidade do local, uma vez que as descrições pretéritas já eram conhecidas em outras cidades (memória).

A segunda cidade referente à temática memória é Isidora. E ela é assim: desejada. Nesse momento, depreendemos uma análise hipertextual, pois a relação temática que se estabelece é entre o desejo e a memória. É a partir da temática memória que o desejo - outra série temática - entra em cena. As cidades e a memória principiam o itinerário, uma vez que é pela memória, pelas recordações que Marco Polo descreve seus roteiros. A complexidade sintagmática implica a urgência de reconhecer Isidora no espaço e no tempo; isso porque nesse momento a isotopia temporal marca de um lado a cidade dos sonhos e de outro, os desejos - temática essa que se apresenta na sequência. A instância temporal delimitada no presente não mais aponta para a cidade sonhada Isidora, mas sim "os desejos agora são recordações" (CALVINO, 1990: 12).

Percebemos entre as cidades e a memória e as cidades e o desejo uma conexão entre palavras e frases "cujos significados remetem uns aos outros, dialogam e ecoam mutuamente para além da linearidade do discurso" (LÉVY, 2010: 73); trata-se de uma rede de associações, o que certifica nossa assertiva de que o hipertexto não se consolida tão somente por suportes virtuais, e sim pelas palavras e suas relações, pelas tramas construídas discursivamente.

A primeira série da temática desejo chama-se Doroteia. Sabendo-se que para Marco Polo “os desejos agora são recordações” (CALVINO, 1990: 12), a memória é presentificada em Doroteia por uma série de fatos distribuídos em um mesmo plano: "no passado no presente no futuro" (CALVINO, 1990: 13) - e sem nenhuma interrupção e preocupação com a enumeração 
do tempo. Quando Marco Polo chega em Doroteia, seu relato é interrompido pelo discurso direto, evidenciando uma voz que cria um efeito de verdade a respeito de Doroteia. Nessa cidade, em primeiro plano, a objetividade demarcada em terceira pessoa denota a distância do narrador no discurso e, na sequência, essa construção cede lugar à sua própria voz traduzida no discurso direto. É como se os sonhos de Marco Polo enclausurados na memória - temática pretérita - fossem substituídos pela consciência e sentimento de estar em Doroteia.

"Cheguei aqui em minha juventude, uma manhã; muita gente caminhava rapidamente pelas ruas em direção ao mercado, as mulheres tinham lindos dentes e olhavam nos olhos, três soldados tocavam clarim num palco, em todos os lugares ali em torno rodas giravam e desfraldavam-se coloridas. Antes disso, não conhecia nada além do deserto e das trilhas das caravanas. Aquela manhã em Doroteia senti que não havia bem que não pudesse esperar da vida. Nos anos seguintes meus olhos voltaram a contemplar as extensões do deserto e as trilhas das caravanas; mas agora sei que esta é apenas uma das muitas estradas que naquela manhã se abriam para mim em Doroteia."

(CALVINO, 1990: 13).

Percebamos no fragmento que ao narrador passar a palavra a Marco Polo em discurso direto - no texto, marcado entre aspas - ele torna evidente sua voz, o que faz emergir do texto o status de verdade. Essa mesma composição prossegue na terceira seção dedicada às cidades e à memória. Zaíra é recebida pela voz de Marco Polo tentando descrevê-la a Kublai. Não se trata, nesse caso, dos segmentos reservados aos diálogos entre os personagens, os quais organizam o princípio e o fim dos capítulos da obra de Calvino: "Inutilmente, magnânimo Kublai, tentarei descrever a cidade Zaíra dos altos bastiões. Poderia falar de quantos degraus são feitas as ruas em forma de escada, de circunferência dos arcos dos pórticos, de quais lâminas de zinco são reco- 
bertos os tetos; mas sei que seria o mesmo que não dizer nada" (CALVINO, 1990: 14). Nessa passagem que abre a terceira seção da temática As cidades e a memória, não há a presença de Kublai, tampouco a utilização de recursos para a marcação do discurso direto. A voz do narrador se apresenta como se fosse parte inerente à descrição posterior: "A cidade não é feita disso, mas das relações entre as medidas de seu espaço e os acontecimentos do passado [...]" (CALVINO, 1990: 14).

No excerto anterior, o narrador instaura uma voz na qual imagina um posicionamento de Kublai Khan. Diferentemente das seções pretéritas, em que Marco Polo descreve as cidades, em Zaíra, a preocupação está em organizar a partir da memória o discurso sobre esse lugar, bem como esperar a resposta de Kublai. É mediante as cidades construídas na memória de Marco Polo que podemos inferir as estruturas hipertextuais nas seções dedicadas às interações entre os personagens.

- Os outros embaixadores me advertem a respeito de carestias, concussões, conjuras; ou então me assinalam minas de turquesa novamente descobertas, preços vantajosos nas peles de marta, propostas de fornecimento de lâminas adamascadas. E você? - o Grande Khan perguntou a Polo. - Retornou de países igualmente distantes e tudo o que tem a dizer são os pensamentos que ocorrem a quem toma a brisa noturna na porta de casa. Para que serve, então, viajar tanto?

- É noite, estamos sentados nas escadarias do seu palácio, inspire um pouco de vento - respondeu Marco Polo. - Qualquer país que as minhas palavras evoquem será visto de um observatório como o seu, ainda que no lugar do palácio real exista uma aldeia de palafitas e a brisa traga um odor de estuário lamacento (CALVINO, 1990: 27).

Aproximamos esse trecho com o excerto inicial da cidade de Zaíra "Inutilmente, magnânimo Kublai, tentarei descrever a cidade de Zaíra dos 
altos bastiões" - (CALVINO, 1990: 14) a partir das relações estabelecidas sintagma e paradigmaticamente. Vejamos que, mediante a pretensão de Marco Polo e a incompreensão de Kublai, os relatos configurados na temática memória induzem à trama da complexidade, e isso, embora se mostre na diversidade de textos que parecem ser independentes, é justamente na incerteza de Kublai quanto aos relatos de Marco Polo que se constroem as passagens para outros lugares e o diálogo entre as cidades. A citação pretérita é uma descrição interessante, pois se configura de dois planos figurativos: de um lado, a insistência de Khan em tornar palpáveis as viagens de Marco Polo, e essa concretude se traduz nos seguintes termos e expressões: carestias, concussões, conjuras, minas de turquesa, preços vantajosos, propostas de fornecimento de lâminas adamascadas. Tais figuras remontam a uma cenografia possível de um mundo real, verdadeiro. Por outro lado, a resposta de Marco Polo não confere com as expectativas de Khan, uma vez que a contestação compreende tão somente a "brisa noturna". Os planos figurativos na passagem orientam para duas cenografias: a do mundo real e a da memória.

Antes de visitar outros tantos lugares, Marco Polo delimita o seguinte trajeto: memória e desejo. Seu itinerário principia na memória e, posteriormente, seu desejo é que sustenta seus inusitados percursos: “[...] enquanto a descrição de Anastácia desperta uma série de desejos que deverão ser reprimidos, quem se encontra uma manhã no centro de Anastácia será circundado por desejos que se despertam simultaneamente" (CALVINO, 1990: 16). Ao mesmo tempo, quando da chegada em Zora, memória e desejo se aglutinam: "Essa cidade [Zora] que não se elimina da cabeça é como uma armadura ou um retículo em cujos espaços cada um pode colocar as coisas que deseja recordar: nomes de homens ilustres, virtudes, números, classificações vegetais e minerais, datas de batalhas, constelações, partes do discurso" (CALVINO, 1990: 19). São essas combinações que resultam uma cenografia construída a partir de um roteiro hipertextual: o eco nascido na memória torna-se nítido no desejo e, assim, visibiliza a passagem às demais cidades. É como se as palavras formassem uma espécie de tessitura, como aponta Lévy (2010). Eis o princípio da constituição do sentido. Falar em comunicação em Cidades invisíveis, sob a ótica do hipertexto, é reconhecer que "os principais operadores desta teoria não serão nem a codificação nem a decodificação nem 
a luta contra o ruído através da redundância, mas sim estas operações moleculares de associação e desassociação que realizam a metamorfose perpétua do sentido" (LÉVY, 2010: 72).

A construção do sentido no recorte realizado para este trabalho - as cidades e a memória, as cidades e o desejo, os diálogos entre Marco Polo e Kublai Khan - depreende-se do cruzamento com as interfaces entre os enunciados isotópicos: a memória que suscita desejo, o desejo que se esconde na memória, e que mantêm uma relação de interdependência.

Coadjuvantes dessa relação, os diálogos entre Marco Polo e Kublai Khan, embora impressionem a ideia de moldura em cada seção temática da obra, denotam que a existência humana não se abrevia a instâncias geográficas.

Marco Polo imaginava responder (ou Kublai imaginava a sua resposta) que, quanto mais se perdia em bairros desconhecidos de cidades distantes, melhor compreendia as outras cidades que havia atravessado para chegar até lá, e reconstituía as etapas de suas viagens, e aprendia a conhecer o porto de onde havia zarpado, e os lugares familiares de sua juventude, e os arredores de casa, e uma pracinha de Veneza em que corria quando era criança.

Neste ponto, Kublai Khan o interrompia ou imaginava interrompê-lo ou Marco Polo imaginava ser interrompido com uma pergunta como:

- Você avança com a cabeça voltada para trás? - ou então: - O que você vê está sempre às suas costas? - ou melhor: - A sua viagem só se dá no passado?

(CALVINO, 1990: 28).

Nesse momento, reportamo-nos à metáfora do teatro que constitui a ideia de cenografia, ou seja, a legitimação de um texto consiste "em sua dupla relação com a memória de uma enunciação que se situa na filiação de outras enunciações e que reivindica ou certo tipo de reemprego." (MAINGUENEAU, 2006: 253). 
Maurília é a última cidade pertencente à temática memória. Nesse momento, a temática memória depreende-se de marcas temporais as quais ilustram duas cenografias referentes a esta cidade: a da memória, esta caracterizada preteritamente e traduzida em "cartões-postais"; e a Maurília atual.

Em Maurília, o viajante é convidado a visitar a cidade ao mesmo tempo em que observa uns velhos cartões-postais ilustrados que mostram como esta havia sido: a praça idêntica mas com uma galinha no lugar da estação de ônibus, o coreto no lugar do viaduto, duas moças com sombrinhas brancas no lugar da fábrica de explosivos. Para não decepcionar os habitantes, é necessário que o viajante louve a cidade dos cartões-postais e prefira-a à atual, tomando contato, porém, em conter seu pesar em relação às mudanças nos limites de regras bem precisas: reconhecendo que a magnificência e a prosperidade da Maurília metrópole, se comparada com a velha Maurília provinciana, não restituem uma certa graça perdida, a qual, todavia, só agora pode ser apreciada através dos velhos cartões-postais, enquanto antes, em presença da Maurília provinciana, não se via absolutamente nada de gracioso, e ver-se-ia ainda menos hoje em dia, se Maurília tivesse permanecido como antes, e que, de qualquer modo, a metrópole tem este atrativo adicional - que mediante o que se tornou pode-se recordar com saudades daquilo que foi

(CALVINO, 1990: 30).

Em Maurília, observamos a seguinte isotopia: de um lado, a cidade dos cartões-postais; de outro, a metrópole. Não há, nesse espaço, um posicionamento que norteia para a preferência: ou a Maurília de ontem ou a Maurília atual. $\mathrm{O}$ discurso orienta - mediante os tempos verbais e marcas que caracterizam as duas Maurílias - para o não isolamento, de modo que o ve- 
lho cartão-postal não necessariamente representa a Maurília provinciana, mas outro espaço que, por acaso, também se chamava Maurília (CALVINO, 1990: 31). É como se cada cidade, ao mesmo tempo que é singular, mantivesse fortemente um vínculo com outros espaços: "No atlas do seu império, ó Grande Khan, devem constar tanto a grande Fedora de pedra quanto as pequenas Fedoras das esferas de vidro. Não porque sejam igualmente reais, mas porque são todas supostas. Uma reúne o que é considerado necessário, mas ainda não o é; as outras, o que se imagina possível e um minuto mais tarde deixa de sê-lo" (CALVINO, 1990: 32-33). Nessa passagem, por exemplo, o desejo em Fedora recupera a isotopia da memória. Não há escolhas ou respostas demarcadas para a significação de cada cidade, o que há é a multiplicidade de percursos figurativos os quais diversificam os efeitos de sentido e também o grau de complexidade. Em termos de enlaçamento, "quanto mais avança no texto, tanto mais o leitor deve convencer-se de que essa cenografia, e nenhuma outra, é compatível com o mundo que o texto exibe." (MAINGUENEAU, 2006: 264).

Lembramos que o texto compreende um dito mais um não dito (MARCUSCHI; XAVIER, 2010). Eis o estrato de leitura de As cidades invisíveis. O hipertexto é assim: uma relação de referências, umas ditas, outras não ditas, e cabe ao leitor traçar o percurso que mais lhe convier. No caso do mistério das cidades conhecidas por Marco Polo, o diálogo entre o dito e o não dito é imprescindível para que o leitor apreenda, ao mesmo tempo, cada detalhe em si, mas que cada singularidade não se finde apenas a "cartões-postais".

\section{CONCLUSÃO}

A proposta deste artigo baseou-se na análise da obra As cidades invisíveis, de Ítalo Calvino, mais especificamente no recorte temático As cidades e a memória e As cidades e o desejo, incluindo alguns excertos dos diálogos entre os personagens Marco Polo e Kublai Khan. Primamos por apenas algumas passagens em virtude da natureza deste trabalho. Seria inviável contemplarmos todas as possibilidades que a literatura de Calvino (1990) proporciona, justamente pelas coerções que o gênero artigo demanda. 
Não obstante a limitação deste trabalho, foi possível concretizar o objetivo de estudo: analisar a(s) cenografia(s) da obra As cidades invisíveis, de Calvino, a(s) qual(is) se constrói(em) de forma não linear, mediante o reconhecimento que o hipertexto se faz presente em um escrito impresso. As teorias que sustentaram a análise permitiram reconhecer que o hipertexto se consolida, antes de tudo, no próprio texto e, desse modo, os enunciados são construídos por meio de cenografias variadas que comportam propriedades hipertextuais. A memória, temática que inaugura as viagens de Marco Polo e que por meio dela viabiliza a descoberta do símbolo, sustenta o desejo e o vínculo com Khan. Assim, analisar a obra em questão careceu instigar as categorias de cenografia, de Maingueneau (2006), e do hipertexto, de Lévy (2009, 2010).

Ainda que nossa análise se abreviou a algumas passagens da obra, em especial das seções temáticas da memória e do desejo, para um estudo dessa natureza, isso revelou-se suficiente para evidenciar a dinamicidade do texto de Calvino (1990). Tal movimentação foi possível de ser mostrada a partir de um roteiro metodológico que primasse por algumas categorias intrínsecas à cenografia ante a proposta de leitura hipertextual.

Desenvolver uma pesquisa dessa natureza significa ressaltar a necessidade de estudos acadêmicos que contemplem a interdisciplinaridade; neste caso, a literatura e a linguística. Além de produtivo, trata-se de uma iniciativa inovadora, pois diz respeito a duas áreas que, cada uma sustentada por teorias próprias, podem olhar para um corpus a partir de algo que ambas têm em comum: a linguagem. Ao analista de discurso, o detalhe das marcas linguístico-discursivas, a visão enunciativa; ao literato, a sensibilidade estética.

Este artigo representa uma contribuição aos estudos que primam por conceber uma obra literária a partir da movimentação da palavra. Em termos de leitura, as noções sobre o hipertexto propiciaram o reconhecimento da obra não mais condensada em suposições rasas de que esse estrato só é possível por meio do aparato virtual. Antes de qualquer tecnologia, é a palavra que consolida o hipertexto. Exemplo disso é a literatura de Calvino; concordemos que seria folclórico tentarmos decifrar o enigmático símbolo das cidades partindo de uma pseudolinearidade, na quimera de encontrarmos exatamente o início, meio e fim do texto. Cidades invisíveis é muito mais do 
que estrutura. É pergunta e resposta. Muito mais pergunta do que resposta. Uma relação que só se constrói mediante o contato com o outro - pela palavra ou pelo silêncio - ainda que esse outro se manifeste tão somente na memória ou no desejo.

\section{REFERÊNCIAS BIBLIIOGRÁFICAS}

BARTHES, Roland. O rumor da língua. São Paulo: Martins Fontes, 2004.

CALVINO, Ítalo. As cidades invisíveis. 2. ed. Tradução Diogo Mainardi. São Paulo: Companhia das Letras, 1990.

CHARAUDEAU, Patrick; MAINGUENEAU, Dominique. Dicionário de Análise do Discurso. Coordenação da tradução Fabiana Komesu. 2. ed. São Paulo: Contexto, 2008.

CHARTIER, Roger. O mundo como representação. Estudos Avançados. São Paulo, v. 5, n. 11, jan./abr. 1991. Disponível em: <www.scielo.br/scielo.php? pid=S0103-40141991000100010...sci...>. Acesso em: 10 mar. 2012.

O que é virtual? Tradução Paulo Neves. São Paulo: Ed. 34, 2009. (Coleção TRANS).

FREITAS, Ernani Cesar de. Linguagem na atividade de trabalho: éthos discursivo em editoriais de jornal interno de empresa. Desenredo, Passo Fundo, v. 6, n. 2, p. 170-197, jul./dez. 2010.

LÉVY, Pierre. As tecnologias da inteligência: o futuro do pensamento na era da informática. 2. ed. Tradução Carlos Irineu da Costa. Rio de Janeiro: Ed. 34, 2010. (Coleção TRANS).

MAINGUENEAU, Dominique. Discurso Literário. Tradução Adail Sobral. São Paulo: Contexto, 2006. 
MARCUSCHI, Luiz Antônio. Linearização, Cognição e Referência: o desafio do hipertexto. São Paulo: PUCSP, 2006. Disponível em: <www.pucsp. br/ fontes/ln2sem2006/17Marcus.pdf >. Acesso em: 10 mar. 2005.

MARCUSCHI, Luiz Antônio; XAVIER, Antonio Carlos (Org.). Hipertexto e gêneros digitais: novas formas de construção de sentido. 3. ed. São Paulo: Cortez, 2010. 
